

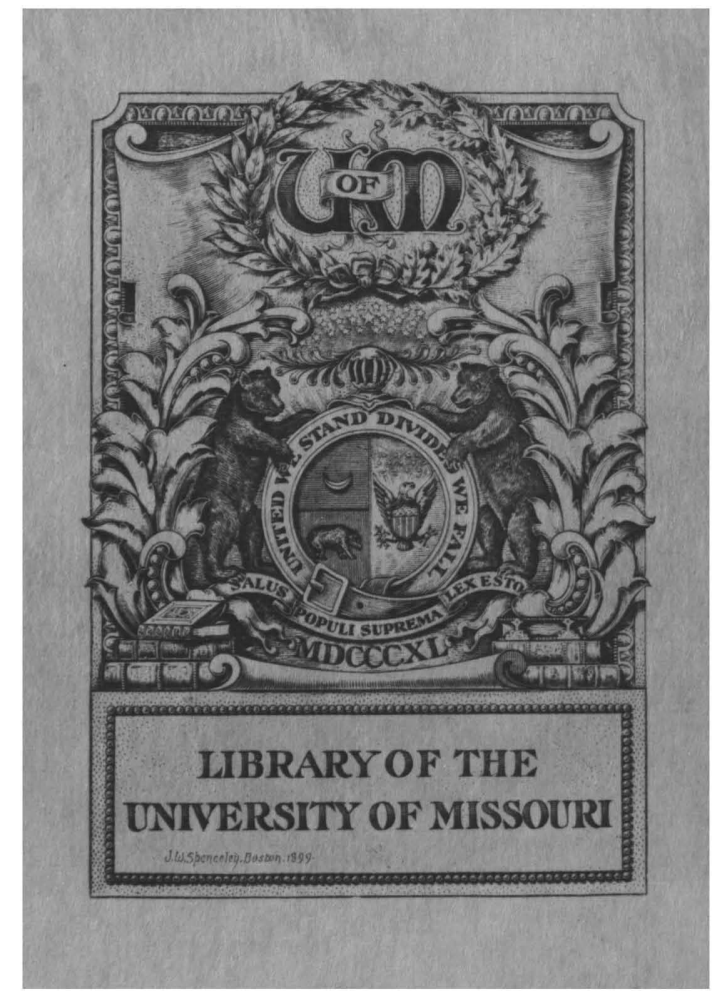

This Thesis Has Been

MICROFILMED

Negative No. T- $\quad 781$

Form 26 








\section{CATHODE DISINTEGRATION}

II

by

Ira Jones, B. S. in Ed.

III

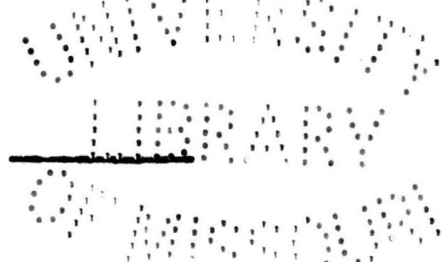

SUBMITTED IN PARTIAL FULFILLMENT OF THE

REQUIREMENTS FOR THE DEGREE OF

MASTTR OF ARTS

in the

GRADUATE DIVISION

( COLLEGE OF ARTS AND SCIENCE)

of the

UNIVERSITY OF MISSOURI

1911.

$-0-$ 

$328.7 m 71$

$\times 0717$

\section{CATHODI DTSTMTEGRATION.}

The use of the disintegration of the oathode in the vaouur discharge for the production of thin metalite flims was first proposed by plücker in 1858. This proposal was firgt carried out by wright ${ }^{2}$ in 1877. Wright showed that if certain metals, platinum etc., are used as the negative terminal in a vacum tube, not only are the gaseous moleoules shot away from the electrode when the discharge is passed through the tube, but the metal eleotrode is so affected that the metalife particles are also shot out and that these particles adhere to any object which they happen to strike. In this way he prepared mirrors from a number of metals which were used as cathode.

In 1886 Kundt $^{3}$ used this method for preparing thin semi-tranoparent metallio mirrors to study the polarizing power of metals upon transmitted and also upon reflected. IIght.

The first quantitative work on cathode disintegration was done by Crookes ${ }^{4}$ in 1891. He compared the disintogration of a large number of different metals and came to

1 J. Plüoker, Pogg. Ann. ov. p. 68 (1858).

2 A. W. Wright, Amer. Journ. of So. \& Arts, (3) xi11. p. 49 and $x 1 v$. p. 169 (1877).

3 A. Kundt, Wied. Ann. xxv11. p. 59 (1886). p. $88,1891$.

4 Crookes, Proceedings of the Royal Soctety, v01. 15,

$$
10480059
$$



the conclusion that the phenomenon is simtiar to ordinary evaporation. To prove this, he showed that water at atmospheric pressure evaporates faster when a wire connected to the negative terminal of an induction coil dips into the water. He also showed that cadmium in a vacuum when heated to near the temperature at which it vaporizes much more rapidly when negatively charged than otherwise. Positive electrification was shown to produce hardly any effect in this respect, and the little effect that was produced was attributed to the leakage of negative electrification from the anode. SiIver was experimented with in the same way except that no heat was applied, and practicaily all the disintegration was found to be produced by the cathode discharge. The observed phosphorescence of the containing glass vessel was found to be produced by the residual gaseous particles of metal shot off from the pole, no metal being deposited in the region of phosphorescence. The order of the metals in descending order of disintegration is given by Crookes. The alloy brass was found to glve a deposit which was the same in composition as the original but gold aluminIurn alloy deposited the gold and left the aluminium behind. Granquist $^{l}$ in 1898 found that the order in which the different metals disintegrate depends upon the pressure of the gas. Thus he found that a platinum cathode lost more

1 G. Granquist, ofvers. af K. Vetenskaps-Ak. Förhandl. p. 709 ( 1898$)$. 

than a gold electrode at high pressure and less at low pressure. He studied the effect of pressure upon the rate of disintegration and gives a series of curves expressing the effect of pressure upon the rate of disintegration for the metals gold, platinum, silver, and copper. He also found that the amount of disintegration is proportional to the square of the current when the pressure is constant. Furthermore, Granquist found that the metal lost in a fer minutes while used as cathode as much as the same metal would in hours when in the form of an incandescent uncharged wire or when used as an anode.

By means of cathodic projection, L. Houllevigue ${ }^{2}$ in 1902 prepared thin flims of platinum, palladium, iron, cobalt, copper, and bismuth. The recelving substance (glass, metalifo plate, \& c.), was placed upon a large hortzontal anode of aluminium, and $12 \mathrm{~mm}$. above this was placed the cathode which was to be disintegrated. The cathode dark space was allowed to come almost in contact with the plate on which the deposit was formed. The deposits obtained presented all degrees of transparency according to the period of operation. A bismuth film showed no variation of electrical resistance in the ragnetic field. Iron when so thin as to be transparent, shored rotation of the plane of polarization when magnetized.

1 Comptes Rendus, 135, pp. 626-627, oct. 20, 1902. 

Holborn and Austin ${ }^{l}$ in 1804 made some very interesting experiments on the amount of disintegration of the cathodes of different metals under similar electrical condtions. They used a constant current density of $0.6 \times 10^{-3}$ amperes per square centimeter of cathode surface. This ourrent density is large enough to make, at the pressures they employed, the cathode fall of potential depend upon the pressure, so that by altering the pressure they could obtain large variations in this fall. The cathode fall pas varied from 350 to 3500 volts. The cathodes used consisted of circular disks of metal hung on vires of the same metal (except that iron wire was used to suspend the cathodes of antimony, blsmuth, zinc, tin, and lead). A disk of mica was placed over the cathode to prevent disintegrated particles being thrown backmard, and the supporting wire was surrounded by a small glass tube.

When the tube was filled with air, they found that $y$, the loss of weight in 30 minutes could for platinum, silver (one sample), copper, and nickel be represented by the formula

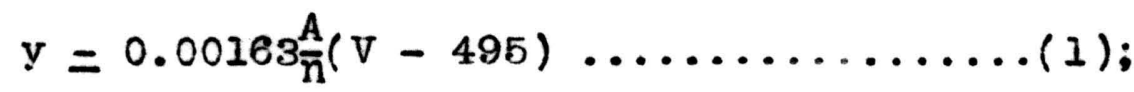

for silver (another sample), bismuth, palladiur, antimony, and rhodium the relation was

1 Phil. Mag., Aug. 1904, p. 145. 



$$
y=0.00187_{\pi}^{A}(v-495) \ldots \ldots \ldots \ldots \ldots . . . . .
$$

$V$ is the oathode fall of potential in volts, $A$ the atomic velght of the metal, and $n$ its valency. Other metals such as Iron, aluminium, and magnesium do not follow etther of these laws, their loss by disintegration being much too small. For those metals which follow the laws (1) and (2) with the same current and cathode fall the weight of the cathode disintegrated is proportional to the weight of those metals which would be deposited in voltameters placed in series with the discharge tube, the weight disintegrated is equal to the amount deposited only for a particular value of the oathode fall. Metals such as zinc, cadmium, lead, and tin, which are readily oxidized, were also investigated, but the oxidation which takes place complicates the results; in the case of zinc, with low potentials, results were obtained which were in approximate agreement with the above equations. In hydrogen the disintegration is less than in air, and the experiments with it did not lead to any regular results.

V. Kohlschütter and R. Müller ${ }^{I}$ in 1906, using wire cathodes in pure gases, showed that when the easily fusible metals lead, tin, and cadmium are disregarded, the order of loss of weight by disintegration in air which Crookes had found for these discharges, is approxtmately - Irtdium does not follow this law - the inverted voltaic series of the

1 Zeltschr. Flektroohem. 12. pp. 365-377, May 18, $190 e$. From the Chein. Inst. $d$. Untv., Strassburg. 

metals. But the phenomena are complicated, because the disintegration does not always begin imnediately after switching on the current; there may be retardation for many minutes. Aluminium, whioh has so far been regarded as practioally Impossible of disintegration, is indeed not disintegrated in the gases hydrogen, oxygen, and nitrogen, but there is some. effect in heliwn, and a strong disintegration is argon and meroury vapor; the retardation in argon lasted in one instance over an hour, after which $0.9 \mathrm{mgm}$. of aluminium was disintegrated in 25 minutes. It was found that iron could be disintegrated only to alight extent, which is practicaliy the same for the different gases. Gas pressure in the tube was found to decrease, as a rule, when the disintegrated particles were allowed to projected only in certain directions, and might increase again and become constant. Bach metal gave in each gas a characteristic pressure ourve. The increase in pressure was attributed to a generation of hydrogen, produced by the electrolysis of hydrogen layers on cathodes of aluminium, cadmium, iron; there was little disintegration with these three. In nitrogen and oxygen the pressure decreased for all the metals, owing probably to chemical combination; in this case the disintegration is strong. With the noble metals,platinum, gold, silver, and mercury, in inert gases and in hydrogen, the pressure soon became constant while disintegration continued. The researches indi-

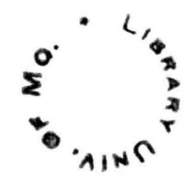



cate that the disintegration depends upon the affinity between the metal and the gas, just as, according to Haber, the cathode disintegration in alkaline liquids starts with the formation of a nitride. The vapor density determinations by Crookes of the volatile metals in helium and argon also show that tin and cadmium tend to combine with these inert gases at 1,200 or 1,300 degrees Centigrade. It is therefore concluded by Kohlschütter that the cathode disintegration is due to the formation of endothermic chemical compounds between the metal and the gas, and that these compounds are decomposed on the cold glass malls of the vessel, leaving metalifo mirrors. The energy required to form the compounds is the kinetic energy with which the carriers of atomic dimensions in the glow discharge strike the cathode. According to this view, canal rays should produce analogous effeots. This was confirmed qualitatively by Kohlschütter' in 1906 ; quantitative experiments could not be made.

The general conclusion, that the cathode disintegration is essentialiy chemical in nature, and that endothermic, volatili metalilo compounds are formed which are subsequently decomposed again is confirmed by further experiments of Kohlschüter and T. Goldsohmidt ${ }^{2}$ in 1908. The reaotions take place between the metal and the positive carriers of the glow discharge whion originate in the negative glow

1 Zeitsohr. Electrochem. 12. pp. 869-973, Nov. 30, 1908. 2 Zeitsohr. Elektrochem. 14. pp. 221-235, April 24, 1908. From the Chem. Inst. d. Univ., Strassburg. 

layer, and which strike the oathode with kinetic energy $\mathrm{E}=\mathrm{eK}$, where $\mathrm{e}$ is the positive unit charge and $K$ the fall of potential; this energy.is in itself great, compared to the mean kinetic energy of gas molecules, and is all the more powerful because directed. Granquist had already shown for low potentials that the loss of welght of a cathode is proportional to the cathode fall, and Holborn and Austin had. demonstrated that the rate of disintegration raselated to the atomic reights of the metal. Kohlschutter and Goldschmidt proved that the inert gases helium and argon act in a manner similar to the other gases. The order in which the gases attack the metals is that of the atomic weights of the metals. The investigation of the chemical nature of disintegration was taken up by F. Fischer and 0 . Hähnel ${ }^{I}$ in 1908. Arranging experiments like those of Kohlschütter and Goldschmidt in a different way, they came to entirely different conclusions. Kohlschütter used one tube in series with a miliameter and a titration coulombmeter for measuring the ourrent in the secondary of an Induction apparatus; Fischer and Hähnel placed two equal tubes in series. They found that the order of disintegration is the same for the two gases, helium and argon. When the gases contain air, less metal is disintegrated; argon is particularly sensitive in this respect. The disintegration increases approximately

1 Zeitschr. Flektrochem. 14. pp. 366-367, July 3, 1908. Preliminary commication from the chem. Inst. d. Univ., Beriin. 

as the square of the current intensity, and is inversely proportional to the gas pressure. When the results of Kohlsohütter are reduced to equal current intensities, the order of the gases, in which they attack the metals, is by no means that of the atomic weights of the metals. When two tubes are coupled in parallel, however, the argon tube shows a much greater disintegration of metal than the hydrogen tube; that is because the current chiefly passes through the argon; with higher potentials, however, the differenoes vanish. There is no proof that the noble gases, neon, krypton, xenon, and helium, form any compounds.

Kohlsohütter (1908) admits that it is advisabie to arrange two tubes is series; the arrangement is inconvenient, however, when several gases are to be tried. Adopting the series grouping for two tubes, charged, the one with hydrogen, and the other with argon, Kohlschütter found in confimation of his previous results, that 20 times more platinum was disintegrated in argon than in hydrogen. Much depends upon the induction apparatus, however, and it was found that with different induction apparatus of the same mean current intensity both the absolute amount of disinte-.. gration and the disintegration ratios for different gases may fluctuate considerabiy. The probable cause of the discrepancy would be that the disintegration is not proportional

1 Zeltsohr. Elektrochem. 14. pp. 417-421, July 31, 1908. 

to 1 , but proportional to $1^{n}$, and that $n$ has different values for the different gases. The fluctuations may completely mask the differences in the behavior of different gases. Fischer and Hähnel ${ }^{l}$ give partioulars of the experiments already noticed, and repeat that they can not accept Kohlschüter's view that the inactive gases become active in the vacuum tubes. Kohlschütter (1908) replies further, and maintains that the differences are due to the different energy consumptions in the two series of experiments; a direct comparison is not possibie, as the exact dimensions of the induction apparatus have not been given. He adheres to his opinIon that a thermal and a chemical effect overlap; the thermal effect would predomlnate with the more volatil metals with whioh Fischer had chiefly experimented.

Fischer and Hăhnel ${ }^{3}$ (1908) continue the controversy by stating that the cathode disintegration in gases is a purely physical vaporization phenomenon. They worked with weaker currents than Kohlschütter. The disintegration is diminished by the formation of oxides or nitrides on the cathode, but there is no proof of the formation of argon compounds such as would justify a chemical theory. Kohlschüter 4 (1908) points out that his currents were not stronger than those of Fischer; the current curve, not the mean

1 Ibid. pp. 433-437, Aug. 7, 1908.

2 Ibid. pp. 437-439, Aug. 7, 1908.

3 Zeitschr. Elektrochem. 14. pp. 677-681, oct. 2, 1908. From the chem. Inst. d. Univ., Berlin.

4 Ibid. pp. 68i-683, oot. 2, 1908. 

Intensity, is the chief feature. B. Walter' (1908) states that the phenomena really depend, not on the quantity of electricity, but on the energy, the product of the quantity by the fall of potential at the csthode, and this fali is smalier in argon than in hydroger.

Kohlschüter2 (1908) continues his experiments mith constant and somewhat stronger curcent. The general results previousiy obtained by Holborn and Austin, by Kohlschütter, and by Goldschmidt are confirmed. The disintegration is proportional to the square of the current intensity and increases rith increasing potential in argon and nitrogen. In hydrogen a maximum disintegration is soon reached. The weights of metals disintegrated at the same current intensity vary as the equivalentis, but different valencies of the metals have to be assumed for the discharges in argon and nitrogen; in argon the metals appear to have the valencies one or two. Peculiarities are noticed in the behavior of platinum and also of other metals. The disintegration decreases throughout in the order argon, nitrogen, hydrogen. The staterent of Fischer and Höhnei that the disintegration would, under equal conditions, become the same in argon and in hydrogen, is not confirmed.

1 Ibid. p. 695, oct. 9, 1908.

2 Zeltschr. Flektrocher. 15. pp. 318-328, May 15,1909. 

The discussion so far has been ooncerned only rith what has been done on the subject of cathode disintegration. There is, however, much left to be done along this Iine. It has been pointed out that the cathode disintegration depends upon the gas present as well as upon the metal of which the cathode is composed. Hence it was thought interesting to investigate whether the gas in which the mirrors rere prepared had any effect upon their reflecting powers for different wave-lengths, especially the short wave-lengths (ultraviolet), owing to the use they might be put to in the construction of interferometers, \& c., for the study of this part of the spectrum. The object, therefore, of the present investigation is to test this point and also to find the conditions best suited for the production of the mirrors.

APPARATUS.- A vacuum apparatus was made by outting a large acid bottle in two with a wire electrioally heatod and using the upper portion. To make a close joint the bottom of the portion used (the vacuum jar) was emery-ground on a plece of plate glass. The cathode terminal was introduced through the ground joint $J(F I g .1,0.13)$, which was mercurysealed. To prevent discharge taking place along the wire it was covered by a small glass tube inside the outer tube, as shown in the figure. The smali neck $N$ was sealed with sealing-wax and the receptacle above was filied with mercury. The oathode was attached to the negative terminal by means of a hook H. The wire immediately attached to the cathode 



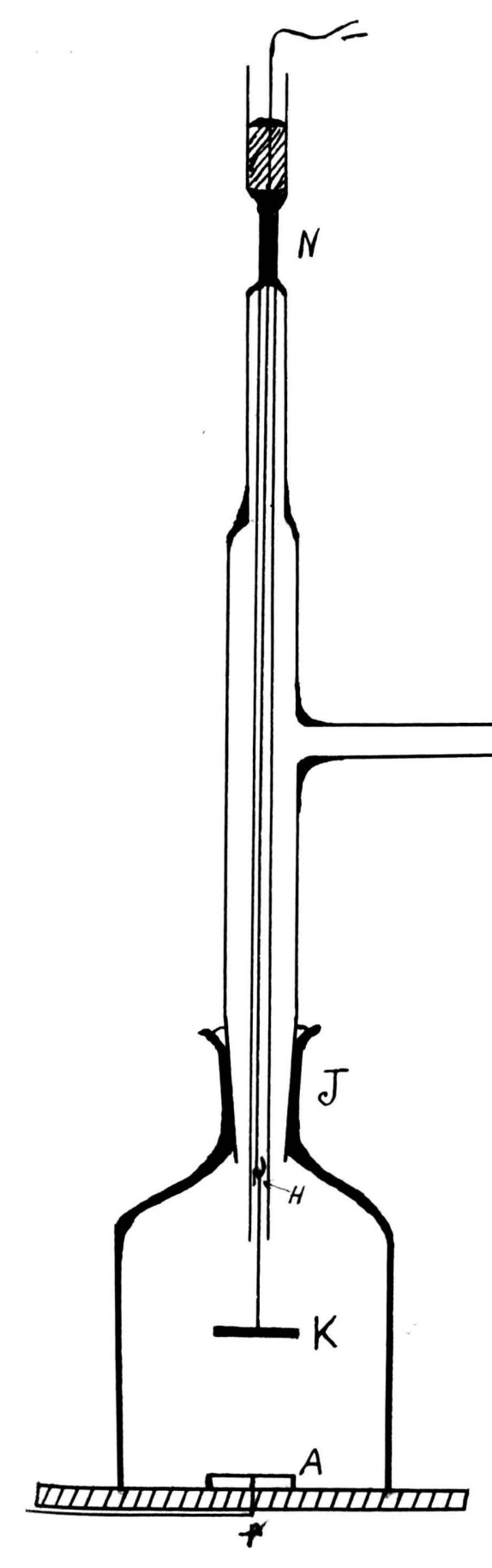

Fig. 1.

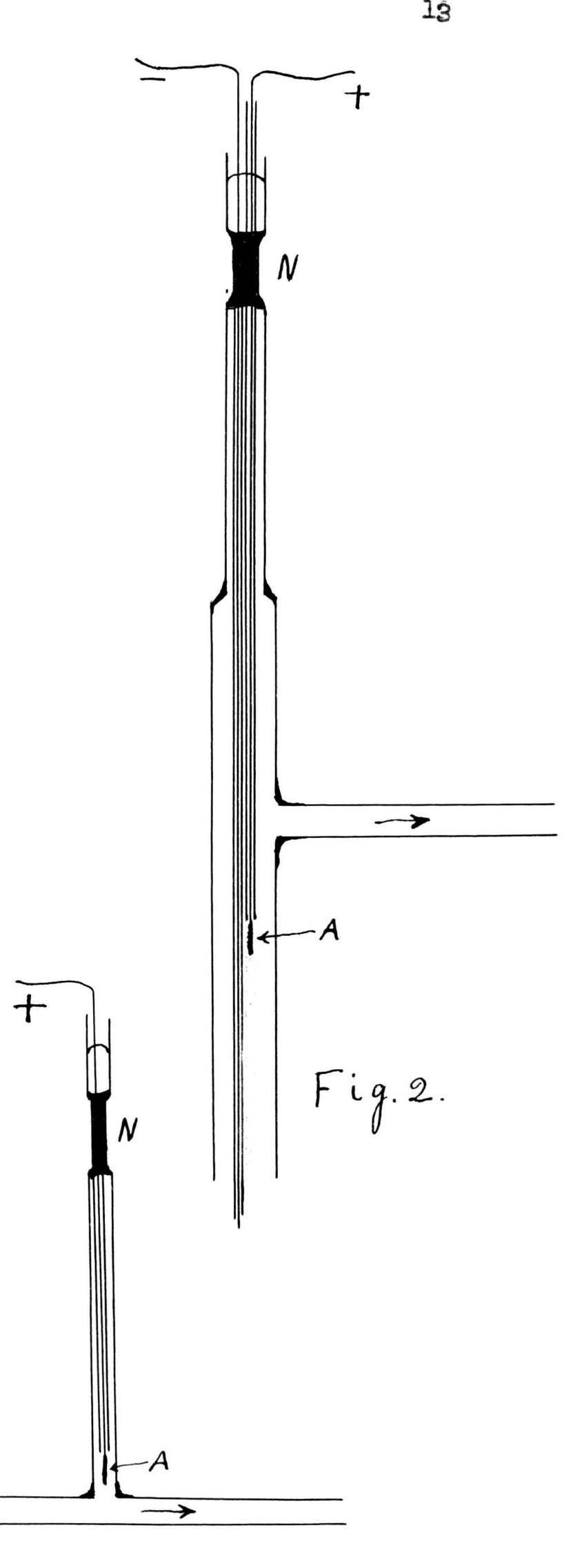

Fig. 3. 

was covered by a glass tube which extended back over the tube through which the wire was introduced. Different methods were used in preventing the backward projection of disintegrated particies at different times. As shown in the figure, the anode is situated on the base plate through a hole in Whioh connection is made with the positive terminal, and the seal is made with Delchotinsky cement. Stop-cock grease was used to make air-tight the joint between the vacuum jar and. the base plate. To prevent the possibility of leakage due to the introduction of the positive terminal through the base plate, and to afford means of studying the effect of the position of the anode on the discharge and the character of mirrors formed, two other methods were used in arranging the anode as shown in figures 2 and 3 , where the anode is the end of a wire introduced from above through an inner glass tube covering it almost to its end. The vacuum jar in figure I is ten om. In diameter and ten cm. high; the one used with the terminals shown in figure 2 is ten om. in diameter and thirteen om. high; that with figure 3 is six cm. in diameter and nine $\mathrm{cm}$. high. A Gaede high vacuum mercury pump tras used, and the joint between it and the vacuum apparatus was sealed with sealing-wax. The ourrent was obtained from an induction coll operated in the 110 volt D. C. oirouit with a Wehnelt interrupter. In order to have a current through the vacuum apparatus in one direction only, a spark gap about 0.8 cr. 

long was kept in series. The electromotive force produced by the induction coil when the oiroult was olosed was strong enough to force a current across this gap but that produced In the opposite direction when the circult was broken was not strong enough to do this, hence ourrent resulted in one direotion only.

Mirrors from each of the metals silver, tin, copper, zinc, and platinum were prepared in each of the gases air, hydrogen, oxygen, and nitrogen. Hydrogen and oxygen were prepared by electrolysis of water. Nitrogen was prepared by heating sodium nitrite with amontum ohloride. Fach gas was coliected over water and dried before being introduced into the apparatus by bubbling it through concentrated sulphuric acid.

MANIPULATION.- When air was used as the working gas the apparatus was first exhausted until the cathode dark space came almost down to the glass (the mirror glass) on which the deposit was to be made, and it was kept at this pressure while the discharge was allowed to pass. With the other gases the apparatus was first exhausted to a high vacuun, a little of the gas introduced by means of a three-way stop-cook, and the apparatus exhausted again. Gas was then admitted again.to atmospherio pressure and allowed to stand about ten minutes so as to let it wash out the apparatus thoroughly. It was then exhausted again and a little more gas admitted. The next exhaustion was followed by the pas- 

sage of the discharge, the pressure being regulated the same as with air. The gas left in the apparatus became contaminated with oocluded hydrogen to a slight extent, but there ras no way to prevent this.

The apparatus shown in figure I was first used in some preliminary experiments and at the last part of the work, as will be explained later. The small vacuum jar was used in the first part of the work of preparing mirrors because of the quickness with which it could be exhausted and beoause a small amount of gas was required. to fill it.

Platinum mirrors were prepared in the small vacuum jar. The disintegrated particles were prevented from being projected backward and to the sides by soreening off with glass coverings. The mirror glass was about $1.2 \mathrm{~cm}$. from the cathode. The cathode in this case consisted of an alusinium oathode covered with platinum foil. There was no diffloulty in getting good mirrors of platinum in any of the gases.

Copper mirrors prepared in this way were clouded in appearance. The best results with copper were obtained by soreening off only the backward projection of the disintegrated particles, by means of a glass plate over the rear of the cathode. The apparatus of f1gure 2 was found most sat1sfaotory. The copper cathode consisted of sheet copper and was supported by means of a copper wire.

Tin mirrors prepared by this method with the appa- 

ratus of flgures 2 and 3 were clouded. Th1s work was done with tin-covered iron (such as is used in making tin cans) in an aluminium suppost for a cathode. Later a cathode was prepared by covering an aluminium oathode with tin foil. with the projection of the disintegrated particies soreened off by a covering over the rear of the cathode only, good mirrors were obtained in hydrogen, oxygen, and nitrogen. The one prepared in air was clouded. The apparatus of figure 2 mas used in this mork. The good results were attributed to the fact that the disintegrated particles rere allowed a wider range for projection. than was the ease with the amalier vacuum jar. The tin foil was found to be not heavy enough to stand the discharge, breaking in the fiddle when only one layer was used, and being pushed. out in the center when more than one layer was used. To obviate this diffioulty a tin oathode was prepared by melting some tin foil, making a thick plate of it, and supporting it in an aluminium holder by means of flanges extending from the lower side of the alumin1um. A good mirror was obtained in air, but in the other gases and at other times in air it was found diffloult and sometimes impossible to get it to disintegrate, the operation belng stopped by the melting of the tin. The tin, being an easily fustble metal, showed a plain case of melting. The distance of the mirror glass from the cathode, about $1.8 \mathrm{~cm}$. , was greater than in former oases because it was necessary to have a high vacuum (oausing the dark space to move out further 

from the oathode) in order to get disintegration.

In the case of silver it was found best to soreen off only the backward projeotion, and the apparatus of figure 2 was found most satisfactory. The mirror glass was kept about $1.5 \mathrm{~cm}$. from the cathode.

Many trials were made with zino with no disintegration. It was finaliy found necessary to have a high vaouum, when the disintegration was very rapid. In this case the cathode got so hot that a glass oovering over it always broke. Mioa was tried for a covering but it was found unsatisfactory. The cathode was left uncovered during the rest of the work. with zinc. In all the work before this the mirror glass was placed about $1.2 \mathrm{om}$. to $1.8 \mathrm{om}$. from the cathode, but 1t was found necessary to inorease this distance considerably in the oase of zinc in order to keep the mirror glass outside of the dark space. All the zinc mirrors required polishing but this was required to a less degree when the glass was kept well outside of the cathode dark space. The distance was made about 3 cin. with best results. The side of the deposit next to the glass formed a beautiful mirror, but it could not be used because the glass would absorb the ultra-violet light. The other side had the appearance of fine white powder, due probabiy to oxidation of the zinc.

To test the refleotive power of these mirrors, a photograph of a speotrum given by reflected light from each of them was taken upon a Cramer speotrum plate by means of a 

quartz spectrograph. A quartz mercury aro, which is rich in ultra-violet, was used as source. On the plate arranged in sultable positions for comparison with the spectra obtained by reflected light were taken a number of spectra obtained from direct exposure to the source of light. The time of exposure was 40 seconds in each case.

The meroury aro gives a line spectrum. An attempt was also made to get results with a continuous spectrum in the same way. The Nernst lamp and Welsbach burner were tried and found unsatisfactory because the shortest wave-length given by them (the same for both), as shown by the photograph1c plates, was about 3125. The oarbon aro was then tried and was found to give the desired short mave-lengths but the work with it gave undecided results, partly at least, because the photographic films used were unsatisfactory, the supply of spectrum plates having been exhausted before we began work with the oarbon arc. Results with the mercury arc only are recorded. The filu side of the mirror was always used for the reflector, because the ultra-violet light would be absorbed by the glass if the other side mere used.

Each metal was taken up separateiy and the spectra obtained by reflection from the mirrors prepared in the different gases were compared.

(1) SILVER. - The mirrors prepared in all the gases air, hydrogen, oxygen, and nitrogen are about the same in reflecting wave-lengths equal to and longer than 3650 . In refleoting wave-lengths shorter than 3650 the mirror prepared 

in nitrogen is the best. showing some reflection of wavelength 2446. The shortest wave-length appreciably reflected by the mirrors prepared in hydrogen and oxygen is about 2500 . The mirror prepared in air is decidediy weaker than any of the other three in refleoting wave-lengths shorter than 3650; it shows no appreclable reflection of wave-lengths shorter than about 2875 .

(2) TIN.- In the visible spectrum and as far into the ultra-violet as wave-length 3341 the mirror prepared in hydrogen is the best reflector, the one prepared in oxygen is second, the one in air third, and the one in nitrogen fourth. There is, however, only a slight difference between the last two mentioned with these wave-lengths, and in the reflection of shorter wave-lengths than 3341 the order of effioiency is reversed, the mirror prepared in nitrogen being better than that prepared in air. The latter shows no reflection of wave-lengths shorter than about 2875 . With wavelengths shorter than 3341 the mirror prepared in oxygen is a slightly better refleotor than the one prepared in hydrogen. The former shows a slight reflection of pave-length 2300 (it gives no appreolable reflection of wave-lengths shorter than this). While the latter does not reflect this wave-length but does refleot wave-length 2446. With wave-lengths shorter than 3341 the mirror prepared in nitrogen is a decidedly weaker reflector than the one prepared in hydrogen. The latter shows refleotion of wave-lengths as short as about 

2400, while 2446 is the shortest wave-length appreclably reflected by the former.

(3) COPPER. - In the visible speotrum and as far Into the ultra-violet as about wave-length 2750 ali the mirrors show about equal reflecting powers except that the mirrors prepared in hydrogen and nitrogen simultaneously show slightly weaker reflections in wave-lengths shorter than 3650 , the former being the weaker of the two in wave-lengths shorter than about 2900 . In reflecting wave-lengths betreen about 2900 and 2400 the mirrors prepared in air, oxygen, and nitrogen are about the same, none of them showing any reflection of wave-lengths shorter than about 2400. With wavelengths shorter than about 2750 the mirrors prepared in hydrogen and nitrogen show considerably weaker reflections than the other two, being about equal to each other. The latter shows no reflection of wave-lengths shorter than 2446 , while the shortest wave-length apparently reflected by the former is 2536.

(4) zINC.- The mirrors prepared in air, hydrogen, oxygen, and nftrogen have about equal reflecting powers in the visible spectrum and as far into the ultra-violet as wave-length 2536, and they are only slightly different for wave-lengths shorter than this. They all show a slight reflection of wave-length about 2275, while the mirrors prepared in air and hydrogen are just slightiy better reflectors of this wave-length than are the other two. None of therr 

show any reflection of wave-lengths shorter than about 2875.

(5) PLATINUM.- The mirrors prepared in air, hydrogen, oxygen, and nitrogen have about the same reflecting powers except that the the mirrors prepared in air and nitrogen show slightly weaker reflections of wave-lengths shorter than 2536. All show some reflection of wave-length about 2275 and none of them show any apparent reflection of wave-lengths shorter than this.

Making a general comparison of the mirrors prepared from the different metals, those prepared from platinum and zinc are about equal as reflectors, and are considerably stronger and go further into the ultra-violet than the mirrors prepared from silver, tin, and copper. The spectra of the light from the platinum and zine mirrors were, however, recorded on one plate and those frothesilver, tin, and copper mirrors on another. Hence nothing conclusive can be drawn from this comparison. The mirrors prepared from silver, tin, and copper are about equal as reflectors over most of the spectrun. The tin and copper mirrors are about equal as reflectors of the ultra-violet, $\prod_{n}^{h} i l e$ silver is only slightly meaker than these in this part of the speotrum.

From the above discussion it is seen that the gases in which mirrors are prepared have an appreciable effect upon their reflecting powers in all parts of the spectrum, but espeolally in the ultra-violet in which we are particularly interested. For refleoting the short wave-lengths it was 

found best to prepare silver mirrors in nitrogen, tin in oxygen, copper in air or oxygen (about the same), zinc in air of hydrogen (about the same), and platinum in hydrogen or oxygen (about the same).

on page 24 is mounted a print from the photographic plate upon which were recorded the spectra obtained by reflected light from the silver, tin, and copper mirrors. The faintest lines on the plate do not show on the print. Henoe It can give the reader only a general idea of the spectra and of their arrangement on the plate for comparison. The mirror from which each speotrum was obtained by refleoted light is marked in line with it.

SUMMARY.

Mirrors were prepared from each of the metals silver, tin, copper, zinc, and platinum by cathode disintegration in the gases air, hydrogen, oxygen, and nitrogen. In preparing them the different metals were found to require different conditions as to screening off the projection of the disintegrated particles, different gas pressure, etc., for best results. Photographs were taken of spectra given by reflected light from them (the quartz mercury arc used as source) and compared, especial attention being given to the relative refleoting powers of the different mirrors for the shorter wavelengths. For refleoting the shorter wave-lengths it was found best to prepare silver mirrors in nitrogen, $t$ in in oxygen, copper in air of oxygen, platinum in hydrogen or oxygen, and zine in air or hydrogen. 





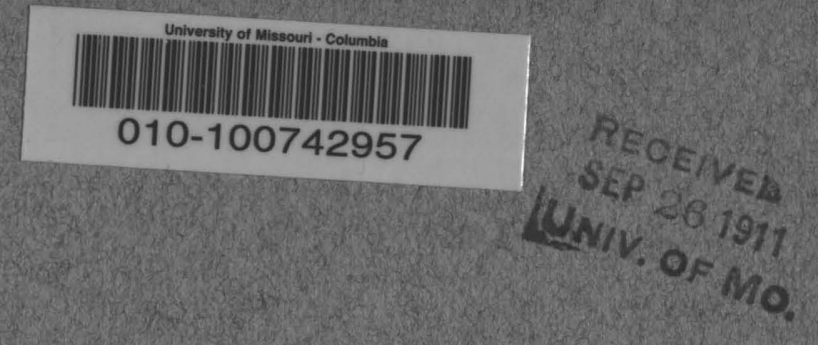

$$
\begin{aligned}
& 378.7 M 91 \\
& \text { i. J } 717
\end{aligned}
$$

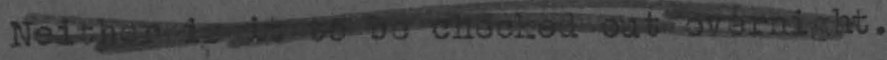


